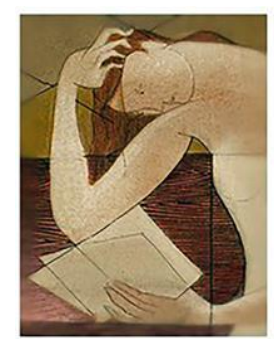

\title{
Lima Barreto e João do Rio: os escritores e seus músicos na cidade
}

\section{Lima Barreto and João do Rio: the writers and their musicians in the city}

\begin{abstract}
Ângelo Chemello Pereira ${ }^{1}$
Resumo: Este trabalho se aproxima da cidade para chegar ao texto literário de Lima Barreto e de João do Rio. Mas também faz o contrário: sai do texto literário e chega na cidade para, através dos autores, realizar uma leitura da vida urbana. O ponto em comum é como se insere o músico carioca nesse lugar que transita entre o literário e o empírico. Ricardo Coração dos Outros é o personagem estudado em Lima Barreto. Em João do Rio a observação se dá sobre os músicos ambulantes. Tais análises serão feitas com uma discussão que envolve o tema da autoria e como o lugar dos autores reflete na escrita de seus personagens.
\end{abstract}

Palavras-chave: autoria; urbanização; músico; centro; periferia

\begin{abstract}
This work approaches the city to reach the texts of Lima Barreto and João do Rio. But also the opposite: it leaves the texts and arrives in the city. That is done to carry out a better reading of urban life through the authors and their time. The common point between Barreto and Rio is how they fit the musicians from Rio de Janeiro in this place wich sometimes seams literary and sometimes seams empirical. Ricardo Coração dos Outros is the character studied in Lima Barreto. On the other hand, in João do Rio the observation is over the itinerant musicians. These analyzes are made in a discussion that involves the theme of authorship and tries to show how the authors' place is reflected in the writing of their characters.
\end{abstract}

Keywords: authorship; urbanization; musician; center; suburb

Centralmente serão dois os textos aqui analisados: Triste fim de Policarpo Quaresma, de Lima Barreto, que é do ano de 1911 e foi publicado em folhetim no Jornal do Commercio; e A alma encantadora das ruas, de Jão do Rio, que reúne crônicas e reportagens veiculadas entre 1904 e 1907 na Gazeta de Notícias e na revista Kosmos. Sendo ambos considerados autores marginais, entendemos que muito daquilo que escreveram pode servir para a compreensão da capital brasileira, o Rio de Janeiro, naquele início do século vinte. O recorte dos anos e a característica dos autores prometem servir como material suficiente para que se faça uma leitura de regiões por onde os músicos marcavam presença. O que se quer é aproveitar o traçado desse mapa (tecido no texto literário) para aprender sobre características da sociedade e alcançar

\footnotetext{
${ }^{1}$ Mestrando em Literatura Brasileira na UFRGS.
} 
lugares urbanos que se transformavam com a modernidade daqueles anos. Cidade, escritores e músicos: é disso que vamos falar.

\section{A cidade do Rio de Janeiro}

"Uma cidade moderna é como todas as cidades modernas" (GOMES, 2005, pg 73). O Rio de Janeiro foi definido assim por João do Rio em sua crônica $O$ velho mercado. Cidade que passou por anos de intenso desenvolvimento durante a gestão de Pereira Passos. Lugar que estava por trás, como cenário em construção, mexendo com Afonso Henriques de Lima Barreto e com João Paulo Alberto Coelho Barreto, o João do Rio. A influência dessa modernização galopante, numa velocidade que para o início do século vinte era intensa e transformadora, não apenas influenciou e afetou a vida dos escritores, como repercutiu nas obras e apareceu como pano de fundo dos textos literários. Tendo esse entendimento, sabemos que a construção narrativa, com sua capacidade de correspondência no modelo social, nos oferece contornos de realidade que permitem a observação das condições de organização física da vida urbana. Sabemos também que existem inúmeros problemas nesse vaivém entre ficção e realidade. Mas é por conta dessa incerteza que a literatura permite avançar de maneira alternativa no entendimento histórico de um local que era então o centro do poder nacional brasileiro.

O texto literário é o que vai nos dar essa orientação? Em grande medida sim - e logo adiante vamos nos aproximar dele —, mas não pensamos que ele seja exclusivo para a análise. Então, com base na leitura, por exemplo, de Lilian Fessler Vaz e Elizabeth Dezouzart Cardoso faremos uso da capacidade arquitetônica e geográfica de captar a cidade. Citaremos (a seguir) como se apresentam os aspectos da capital brasileira daquele tempo em que acontece a escrita dos autores. Isso servirá para que possamos realizar uma espécie de correspondência entre o planejamento urbano e o entendimentos das características que podem estar incidindo sobre a criação ficcional. Entendendo que as obras da cidade moviam as pessoas de lugar e também provocavam deslocamentos espaciais, talvez possamos demonstrar aspectos que permitam também compreender alguns dos personagens e suas características. Na relação entre o texto e o que acontece na vida, possivelmente tenhamos respostas importantes na leitura que os autores fazem a esse respeito.

Mas que Rio de Janeiro era esse? Vejamos incialmente, a partir do recorte extraído do texto das já citadas autoras Vaz e Cardoso, o que percebíamos que estava 
em modificação. A análise faz entender um ponto de vista possível para o ambiente que se instalava.

É preciso ter em conta que a cidade iniciava a expansão residencial nas direções norte e sul; o Centro e adjacências concentravam todo tipo de atividades, inclusive a moradia. Os transportes coletivos eram lentos e caros; um serviço ao qual a maior parte dos trabalhadores, mal remunerados e submetidos a longas jornadas de trabalho, não podia recorrer. Oficinas, manufaturas e pequenas indústrias, comércio e serviços e ainda as atividades ligadas ao porto concentravam-se nas freguesias centrais. Impunha-se aos trabalhadores morar junto ao trabalho, ou seja, o mais próximo possível dessas áreas. (VAZ; CARDOSO, 1985, p. 617)

De saída já encontramos boa demonstração de como era difícil a condição daqueles que precisavam de transporte público. Também temos ciência de que um lugar como o Rio de Janeiro só se transformava em espaço possível para os trabalhadores quando encurtava as distâncias entre casa e trabalho. As mudanças tinham uma interferência nesse modelo que estava consolidado à época. Então alguém provavelmente estava prestes a sofrer as consequências desse avanço.

Toda uma vasta gama de "desfavorecidos da fortuna" se abrigava onde fosse possível: nos dormitórios, nos depósitos, nas lojas, nas oficinas, nos fundos, nos sótãos, nos vãos e nos cantos. E principalmente no tipo padrão de habitação popular do Rio Antigo: o cortiço. Foi este o termo que se generalizou no Rio para denominar as habitações populares coletivas; à medida que se difundia, o termo adquiria forte conotação depreciativa. Eram duas as formas características: a estalagem, uma sucessão de casinhas precárias ao longo de um pátio ou corredor, e a casa de alugar cômodos, prédio antigo subdividido em cubículos. As instalações sanitárias coletivas, insuficientes e precárias, e o acúmulo de moradores por quarto eram o denominador comum. À medida que se adensava a população, pioravam as condições de salubridade, insatisfatórias e constantemente agravadas pelas epidemias. As doenças epidêmicas faziam muitas vítimas onde houvesse maior aglomeração de pessoas e piores condições de higiene. A relação entre o cortiço e a doença foi rapidamente detectada; mas acreditava-se que a relação fosse causal - o cortiço seria o causador da doença. E por isso deveria ser eliminado. (VAZ; CARDOSO, 1985, p. 617)

Como vale enfatizar, está apresentado o cenário da decadência que se relaciona à pobreza. Se essa pobreza é vista como causa da doença, então ela se torna uma importante chaga a ser eliminada, dando argumentos para que o ambiente entre em processo de metamorfose. Mudança exigida para dar conta da saúde pública, uma situação considerada emergencial. Então se dificulta qualquer possibilidade de ir contra um ponto de vista médico, um argumento da ciência que se sobrepõe aos demais casos particulares. Assim sendo, a solução toma forma com base em uma razão acadêmica, um conhecimento que atesta a existência de diferenças justificáveis entre as pessoas. Tem-se, portanto, que a pobreza é o problema e que a reparação vem com a atitude de expurgá-la. A meta elitista passa a mirar a eliminação da presença dos menos 
favorecidos que se encontram nesse lugar central da cidade, uma gente desconsiderada pelo poder público quando a necessidade é a de manter o privilégio de quem já o tem. É sintomático, quando visto pela elite incomodada, que se queira retirar os pobres do lugar onde estão. Por isso a ação articulada vem carregada de critérios higienistas e dessa maneira pode-se embasar a decisão de jogar os desalojados a uma distância incapaz de interferir no cenário ocupado pela riqueza.

Apenas para dar um breve contexto ao já citado formato dos cortiços, talvez seja bom entender que essas moradias estão bastante ligadas às relações anteriores desta cidade em transformação. É importante mencionar pontualmente que o que antecipa a organização desse cenário urbano está ligado à vinda da família real portuguesa, lá em 1808. Ela que trouxe construções e novidades que o Rio de Janeiro, assim como o país, antes não possuía. Lugares aristocráticos no tempo de D. João VI, mas que no período republicano terminaram por perder a pompa inicial. Com o passar de um século os então imponentes sobrados do "tempo do rei" (MACEDO, 2010, p.13) acabaram transformados em moradia coletiva. As grandes habitações de outrora servem, na virada daquele século, para acomodar os trabalhadores de uma classe de baixa condição econômica. O que acontece já nos anos 1900 é que tais modelos, os cortiço, encontramse no espaço onde não podem estar. E são, segundo as forças do novo modelo governamental, um tipo ultrapassado de habitação que precisa ter fim. E o que foi feito com muito desses locais? Vejamos:

Como resultado, temos uma melhor compreensão de como a demolição de quase seiscentas construções, no que ficou conhecido como bota-abaixo, levou a uma degradação das condições de vida de um grande número de pessoas e permanece profundamente interconectado com o crescimento das favelas. (CARVALHO, 2019, p. 125)

O bota-abaixo do prefeito Pereira Passos é emblemático nesse sentido. Como é sabido, as políticas de modernização que transformam espaços urbanos empurram novos desabrigados, os pobres antes moradores desse centro, para regiões bem mais afastadas. A formação de conjuntos habitacionais então passam a tomar forma na margem da cidade ou nos morros. São essas áreas que passam a ser ocupadas para dar início aos novos aglomerados humanos.

Entendido esse movimento podemos dar um passo seguinte. Uma transição pode ser feita para os autores que estamos observando. Se a cidade que eles habitam é a cidade que eles escrevem e descrevem, talvez tais componentes possam ser aproximados. Pois Lima Barreto e João do Rio sofrem os impactos e reconhecem as 
interferências que são implicadas nos personagens desse Rio de Janeiro. Sabendo disso temos que nos aproximar de suas histórias particulares para desembocarmos em seus textos.

\title{
2 Os autores na cidade
}

\begin{abstract}
Se João do Rio posiciona a si mesmo, cuidadosamente, como um forasteiro ao visitar o bairro, para facilitar um sentido de cumplicidade com o leitor voyeur, na ficção de Lima Barreto, pela primeira vez, vemos a região não apenas situada no centro de uma narrativa, mas como sendo o próprio sujeito. (CARVALHO, 2019, p. 156)
\end{abstract}

Ao apontar para essa distinção entre João do Rio e Lima Barreto queremos fazer uma pequena incursão ao tema da autoria. Depois da cidade e antes do texto literário, a figura criativa do autor é um fator fundamental a ser observado. Se existem considerações que distinguem os escritores, muito provável que na obra essa distinção seja revisitada. Mas a propriedade do texto é um valor que remete a quem o produz, por isso mesmo cada um dos dois autores aqui mencionados merece que suas figuras sejam, no mínimo, apresentadas. Tal apresentação se faz ainda mais necessária quando estamos tratando de problemas sociais que se deparam com temáticas de gênero, de etnia e de posição social. É importante que façamos sempre a pergunta: quem é o autor? Porque essa resposta acaba norteando também as consequências estéticas com as quais vamos nos deparar no texto. Há coerências e coincidências que se manifestam por quem escreve por conta de suas reflexões sobre a sociedade, principalmente quando essa expressão artística se dá em uma condição como a brasileira. Poderíamos usar Aníbal Quijano (2000), sociólogo peruano, como referência. Apoiando-se em sua elaboração, entendemos que nossa constituição, nossa formação nacional é carregada de colonialismo e oriunda de uma relação entre conquistador e conquistado. Sendo assim, nada mais necessário do que dar relevo às figuras que escreveram na adversidade de um país recém proclamado república, recém saído de um regime de escravidão.

Não estamos aqui definindo uma regra imutável e tentando estabelecer correspondências diretas, sem mediação, entre a vida dos autores e seus textos. Entretanto, como diz Bruno Carvalho na citação anterior, os autores que estamos analisando estão atuando em condições específicas. Nós temos obrigação, como pesquisadores, de olhar o quanto eles são diferentes entre si e como lidam com seus objetivos particulares. Temos que nos atentar, e isso importa muito, que suas inserções se dão em escalas da sociedade que chegam a se corresponder, mas que nem sempre 
ocupam os mesmos ambientes. Refletindo e entendendo sobre esse ponto segue sendo necessário que se destaque: não é por estarem afastados em certos temas que Lima Barreto e João do Rio ocupam posições confortáveis. São, sim, duas figuras controversas e que desviam do pensamento estabelecido (pelo poder estatal e pelas elites) a partir de seus escritos. A visível antagonia entre ambos não esconde uma quantidade interessante de autoria crítica nos dois autores. Expressão que se dá inclusive na manifestação ficcional de suas personagens. $\mathrm{O}$ que temos nos músicos que virão a seguir, por exemplo, talvez possa apresentar essa capacidade analítica, que é sempre uma leitura de mundo e pode se dar de forma destoante a partir dos critérios de cada autor. São tais características que se salientam de maneira relevante para o estudo, porque revelam a riqueza dos personagens apresentados aos leitores. Daqui, à distância no tempo, podemos dizer que Lima Barreto e João do Rio servem para a história da literatura como exemplos de grande ação política e foram transformadores na maneira de pensar. Inclusive, se formos no atentar para a maneira que se manifestavam, podemos nos apoiar no texto da autora panamenha Lynn Hunt (2009), que ao tratar dos direitos humanos dá conta de mostrar o quanto a proclamação de tais direitos foram gerando alterações sociais gradativas e em escalas diversas da organização social. O que isso gera? Uma continuidade progressiva do pensamento com ações de ruptura com o que está estabelecido. É isso que altera as condições entre os indivíduos da sociedade e permite que vozes antes silenciadas comecem a exigir sua participação nas decisões de uma nação. Esse tipo de rompimento e de avanço é o que vem desaguar nos escritos dos dois autores brasileiros. Eles são um exemplo de mentes individuais que se alteram em um conjunto nacional para atuar sobre a perspectiva brasileira, tornando evidente aquilo que não estava nítido para muitos da mesma época.

Quando Lima Barreto e de João do Rio são escolhidos como peças importantes no cenário deste estudo, eles nos permitem alcançar o entendimento mais aprofundado da cidade que retratam. É necessário admitir (e repetir) que estamos lidando com uma literatura considerada marginal. E isso é dito não para manter a segregação que a história literária consolidou, mas para reconhecer e tentar trabalhar na inclusão cada vez maior de nomes renegados. Fazendo esse movimento, queremos tornar um pouco mais evidente a importância de se discutir Lima Barreto e João do Rio lado a lado. Em grande medida porque os centros de poder configuram como relevante um outro tipo de valor estético. Contrariando tais congelamentos que fazem estagnar nossa compreensão, é com a valorização dessas figuras que se entende melhor o lugar em que eles estão 
atuando. Com os autores dessa esfera excluída nasce também a visão descentralizada, a capacidade de superar uma condição adversa. Ainda mais quando sabemos que foram rotulados - pela sexualidade e pela cor da pele, no caso de João do Rio, e pela cor da pele, no caso de Lima Barreto.

Para constatar tais condições, vamos à citação de Bruno Carvalho. O estudioso inicia, no trecho a seguir, uma descrição que remete a Lima Barreto e, logo em seguida, demonstra a diferença dos olhares sociais na comparação que faz com João do Rio. Estão salientadas as questões étnicas e de gênero a que fizemos referência anteriormente:

\begin{abstract}
Morador do bairro suburbano de Todos os Santos, seus trabalhos eram ocasionalmente publicados pela reconhecida Garnier, da rua do Ouvidor, enquanto lidava com o sentimento de ser um estranho nos círculos literários ali centralizados. João do Rio, por exemplo, apesar de ter sido atacado algumas vezes com conotações raciais e homofóbicas por contemporâneos importantes (como Monteiro Lobato), foi aceito pela venerável e conservadora Academia Brasileira de Letras em 1910. O relacionamento de Lima Barreto com o establishment literário, pelo contrário, era bem mais turbulento: ele foi rejeitado três vezes pela ABL e era com frequência acusado de ser um "mau escritor", em parte devido a sua prosa coloquial. (CARVALHO, pg 153)
\end{abstract}

Mas por que tratar desses aspectos de autoria antes da introdução do texto literário propriamente dito? Porque entendemos que se compreende melhor uma obra quando também se compreende o autor e sua posição de cidadão excluído. Sabemos mais sobre a história literária quando também sabemos quem escreve essa história, quando reconhecemos o nome que deixou ali seu relato. E antes de elevar ou rebaixar um texto temos que constatar que o período histórico é também responsável pela produção que deixa como legado. E é com esses autores marginalizados que não pretendemos omitir que o Brasil é, sim, um país que segrega e discrimina. Para de saída já reconhecer que na história da literatura existe um deslocamento de figuras sujeitadas à periferia do mundo da escrita. Se foram assim, vistos como marginais, aqui neste trabalho são postos em lugar de necessária evidência. É através deles que veremos como se alcança um Rio de Janeiro que não lida apenas com a transformação para os bem vividos, para as classes bem posicionadas economicamente, para os brancos majoritariamente. Importa que se diga isso? Importa. O Rio de Janeiro é mais complexo e mais revelador quando se olha para para os lados, para os que vivem na (ou chegam da) periferia, para os que precisam perambular entre lá e cá. Dessa movimentação que acontece, temos um bom caminho para pensar quem foi João do Rio e quem foi Lima Barreto. 


\section{Um pouco de João do Rio}

Não é o propósito aqui desenvolver um trabalho que dê conta da biografia de João do Rio, por isso vamos apenas dar um panorama de sua história para que também se entenda a cidade em que ele está vivendo. Aliás, esse talvez seja um caminho para poder captar seu olhar sobre os músicos da cidade que abordaremos logo a seguir.

Nascido em 5 de agosto de 1881, ele foi batizado João Paulo Alberto Coelho Barreto. Seu pai era um gaúcho de São Leopoldo, matemático-positivista, chamado Alfredo Coelho Barreto. Sua, dona-de-casa, mãe se chamava Florência dos Santos Barreto. A primeira publicação do autor aconteceu em A Tribuna. Logo depois ele publica no periódico de José do Patrocínio (A Cidade do Rio) e acaba se profissionalizando como colaborador de jornais como $O$ Paiz, O Dia, O Tagarela e Correio Mercantil. Em seu primeiro conto de título "Impotência" escreve sobre repressão e desejo homoafetivo. Em 1902 tenta sem sucesso entrar para a diplomacia, sendo barrado pelo barão do Rio Branco. Segundo Raúl Antelo, isso se dá por João do Rio "não condizer com o figurino do Itamaraty" (ANTELO, 1997, p. 28). Sabemos nós que a afrodescendência e a questão homossexual foram determinantes para tal interrupção da carreira política. Consta também que foi propagandista das reformas do bota-abaixo na revista Kosmos e que em 1905 começam suas candidaturas para a Academia Brasileira de Letras — cadeira que João do Rio só vai ocupar em 1910.

O autor, segundo afirmações de Renato Cordeiro Gomes, foi "o primeiro grande repórter brasileiro do início do século XX" (GOMES, 2005, p. 11). João do Rio tinha uma escrita vertiginosa, era cronista de habilidade e velocidade com grande capacidade de revelar as transformações da cidade, um Rio de Janeiro que conta como o avanço invasivo da modernidade que se estabelece em variados lugares do mundo.

\footnotetext{
$\mathrm{Na}$ cidade em mudança, vai buscar a matéria de suas reportagens: o crime, a miséria, o delírio, os mistérios, as artes e tradições populares, que iam desaparecendo por ação de um cosmopolitismo patrocinado pelo projeto oficial de modernização. (GOMES, 2005, p. 25)
}

O autor trazia uma característica mundana em sua escrita, talvez por isso mesmo tenha sido bastante ignorado. Sua produção dava conta de retratar perambulações pelas ruas e becos sórdidos da cidade e uma capacidade de gerar certa simbiose de estilos, na mistura entre o ficcional e o documental. Uma habilidade que nos faz perceber uma oscilação que ora parece reportagem e ora parece conto. Por esse aspecto temos relatos sobre João do Rio feitos por Carlos Drummond de Andrade. O célebre poeta, que escreveu o texto João do Rio na vitrina, ensaiou uma espécie de manifestação 
intencionada em dar relevo ao autor que estava caindo no esquecimento. $\mathrm{O}$ estilo ambivalente fez com que Drummond o chamasse de "escritor-jornalista, mais do que jornalista escritor" (GOMES, 2005, p. 12).

João do Rio é pseudônimo. Apenas um de tantos outros como Joe, barão de Belfort, José Antônio José e Máscara Negra. Tanta diversidade de personas deixa pensar que João Paulo Alberto Coelho Barreto, seu nome de nascimento, precisasse sempre construir personagens de si mesmo. Somemos a isso o fato de ser homossexual e afrodescendente nessa cidade que avançava em progresso material, mas que permanecia ensopada de preconceitos e discriminações. Foi alvo de injúrias que se repetiram e que o fizeram sofrer com crueldades marcadas pelo peso das diferenças estabelecidas a ponto de suportar deboches diários em uma vida cercada de constantes atos de violência física e verbal. Faleceu dentro de um táxi, em 1921, de uma morte do coração. Mas o personagem ainda vivo, o que adota o pseudônimo de João do Rio e que estudamos aqui, nasceu quando? "Em 1903, nasce João do Rio, com o artigo O Brasil lê, enquete sobre os autores preferidos do leitor carioca" (GOMES, 2005, p. 17).

\section{Um pouco de Lima Barreto}

Vamos abrir este tópico sobre Lima Barreto citando Lilia Moritz Schwarcz. A crítica e biógrafa do escritor o descreve como "afrodescendente por origem, opção e forma literária" (p. 10). O estudo de Schwarcz, em trabalho publicado em 2017, se intitula Lima Barreto: triste visionário e esmiuça em mais de seiscentas páginas a vida do escritor carioca. Um projeto que reafirma e continua a pesquisa Vida de Lima Barreto, de Francisco de Assis Barbosa, autor responsável pela recuperação da obra de Lima Barreto já nos anos 1950. Nascido em 13 de maio de 1881, no considerado arrabalde das Laranjeiras, Afonso Henriques de Lima Barreto foi filho de João Henriques de Lima Barreto com Amália Augusta Pereira de Carvalho. A mãe, uma professora e ex-escrava alforriada; o pai, tipógrafo e filho de um português com uma escrava. A perda da mãe é bastante prematura, ainda aos sete anos de idade. Órfão, o menino se muda nos anos 1890 por conta do emprego do pai, junto com a família, para a Ilha do Governador. Que trabalho era esse? Um emprego como escriturário nas Colônias de Alienados após pedir demissão da Imprensa Nacional. É bom que se destaque esse ponto:

As Colônias de Alienados eram caracterizadas como estabelecimentos agrícolas, nos quais os pacientes desenvolviam sua terapia médica a partir do trabalho, que representava igualmente um modo de custear a internação e o tratamento. $\mathrm{O}$ 
relatório de 1891, por exemplo, informa que, nas colônias, 'os 132 alienados hoje ali existentes empregam-se, com raras exceções, no amanho das terras na cultura dos cereais, legumes etc., e na criação de animais e aves domésticas'. Não era só no Brasil que esse tipo de tratamento vinha sendo adotado. A tese foi defendida no Congresso Internacional de Alienistas, realizado em Paris em 1889, quando se definiu o labor manual como uma forma de recuperação moral dos alienados. (SCHWARCZ, 2017, p. 87)

Estando em Niterói para os estudos, aos doze anos, Lima se depara com a Revolta da Armada. A ilha em que moram os familiares é tomada pelos revoltosos e o fato resulta na escrita de uma carta ao próprio pai. $\mathrm{O}$ autor tem uma vida escolar bastante irregular e uma organização familiar com processos bastante difíceis. Um dos casos mais emblemáticos é o diagnóstico de problemas mentais de João Henriques. Tal condição, em uma mudança residencial para o subúrbio de Todos os Santos, faz com que os Lima Barreto tenham a residência intitulada como "a casa do louco".

Para fins reflexivos é bom que se considere uma ideia: com a proximidade da virada do século, podemos notar que o contexto higienista e a série de definições médico-urbanas caem em sintonia com as consequências da história biográfica de Barreto. O que deixa possível o paralelo entre o que acontece com a cidade e o que acontece nos exílios (se é que podemos chamar assim a ação gentrificadora) da família Lima Barreto. As constantes internações, os repetidos diagnósticos e a possível transferência para os lugares mais remotos da cidade não podiam ser mais evidentes do que foram.

$\mathrm{Na}$ área literária, também um campo excludente e espinhoso, Lima Barreto termina publicando seus textos em diferentes veículos. Dentre eles estão o Correio da Manhã, a Gazeta Tarde, O Copacabana, O Fluminense, a revista Fon-Fon e a revista Floreal (que também é dirigida por ele). Assim como João do Rio, foi usuário de diversos pseudônimos: J. Caminha, Xim, Jamegão, J. Hurê entre outros. Em sua escrita, o combate ao preconceito racial é uma de suas bandeiras constantes. Uma luta incessante e bastante cansativa, que sem dúvida gera grande quantidade de sofrimento. A carga de tamanha distinção é tão intensa que Lima Barreto chega a registrar em seu diário pensamentos suicidas depois de enfrentar problemas por conta da diferença étnica.

Depois de ser desconsiderado e de realizar movimentos críticos contra a Academia Brasileira de Letras, começa a escrever Triste fim de Policarpo Quaresma. O ano de início do folhetim é em 1911, mas a publicação do livro de mesmo nome sai em 1915. Em 1918, trabalhando pela Secretaria de Guerra, solicita aposentadoria por 
invalidez e $\log 0$ em seguida é diagnosticado com epilepsia tóxica. Por conta de seu alcoolismo a cadeia de problemas é inumerável e suas seguidas crises acabam por leválo ao Hospital de Alienados com o diagnóstico de surto psicótico. Embora vivendo constantemente em crise, Lima Barreto mantém uma constância bastante intensa de publicações. Não deixa de escrever e segue assim inclusive nos períodos em que esteve internado. Foi autor de mais de uma dezena de obras, dentre elas as publicadas em vida como Recordações do Escrivão Isaías Caminha (1909) e Numa e Ninfa (1915), e dos publicados após sua morte, como o incompleto Clara do Anjos (1948) e Marginália (1956). Em 1922 morre, em casa, de "gripe torácica".

\begin{abstract}
Afonso Henriques de Lima Barreto foi, provavelmente, o mais ativo crítico da Primeira República e das reformas de Pereira Passos entre os escritores brasileiros. Ele denunciou as hipocrisias da belle époque, evocando-a como nada mais do que uma fachada, simbolizada pela construção da avenida Central, após o que o Rio de Janeiro se transformou em outra cidade. (CARVALHO, 2019, p. 152)
\end{abstract}

\title{
5 Dos autores-escritores para os personagens-autores
}

Apresentados os autores passamos a uma incursão ao que nos serve de ponto focal: o texto literário. A noção de recorte social aqui se afunila para a matéria escrita e tem a ideia de revelar condições que se apresentam no objeto estético e em seus personagens. Principalmente para mostrar como isso está bastante relacionado ao que ronda cada escritor e como neles a vida incide com influências importantes. Lembrando sempre que saímos de uma parcela que nos deu um breve entendimento da cidade e que convergiu para a capacidade de compreender esses autores (por mais resumida que tenha sido nossa exposição). Foquemos então nos músicos apresentados como personagens.

Tanto Ricardo Coração dos Outros, em Triste Fim de Policarpo Quaresma, quanto os músicos da crônica Músicos Ambulantes, de João do Rio, são material apropriado para descobrir qualidades específicas da autoria. Mais ainda, é com esses personagens que podemos perceber a impressão de certas características que se fazem agir pelo contexto vigente. Estamos certos de que o ambiente gera uma capacidade de moldar e de definir o que se expressa no texto. Vamos, por isso, ao olhar os personagens-autores (e aqui nos referimos aos músicos), perceber a cidade que se manifesta por conta do olhar dos autores-escritores (Lima Barreto e João do Rio).

Faz-se necessário um certo parêntese explicativo para essas nomenclaturas que surgem. Autor-escritor e personagem-autor são possivelmente derivações intuitivas que nascem da influência de Mikhail Bakhtin e que estão mais bem explicadas por Carlos 
Alberto Faraco em seu texto Aspectos do pensamento estético de Bakhtin e seus pares. Nesse estudo Faraco ajuda a compreender como o crítico russo separa autor-pessoa de autor-criador. E como essas variações sempre desviam aspectos da realidade tornando possível a associação, mas também deixando evidente que se tratam de figuras separadas.

\begin{abstract}
Para entender melhor essa engenhosa solução, é interessante partir da distinção que Bakhtin faz, já no início de seu texto "O autor e o herói na atividade estética”, entre o autor-pessoa e o autor-criador (Bakhtin, 1990, p.10). O primeiro é o escritor, o artista, a pessoa física. O segundo é a função estético-formal engendradora da obra, um constituinte do objeto estético, um elemento imanente do todo artístico. Trata-se, mais precisamente, do constituinte que dá forma ao objeto estético, o pivô que sustenta a unidade arquitetônica e composicional do todo esteticamente consumado. $\mathrm{O}$ autor-criador é entendido basicamente como uma posição estético-formal cuja característica central está em materializar uma certa relação axiológica com o herói e seu mundo. E essa relação axiológica é uma possível dentre as muitas avaliações sociais que circulam numa determinada época e numa determinada cultura. É por meio do autor-criador (do posicionamento axiológico desse pivô estético-formal) que o social, o histórico, o cultural se tornam elementos intrínsecos do objeto estético. (FARACO, 2011, p.22)
\end{abstract}

A referência é importante pois se atravessa e conduz a um sentido que estamos querendo construir com os personagens de Lima Barreto e de João do Rio. Como isso se dá? Sabemos que o autor-escritor está neste pensamento em um lugar similar ao do autor-pessoa de Bakhtin. E que o personagem-autor, músico desse mundo ficcional, está para o autor-criador (embora divergindo dele) trazendo certas condições de similitude que permitem visualizar as interferências que vem da função estético-formal que toma forma na composição do texto. É importante que se mencione que o personagem-autor é o músico narrado em terceira pessoa, por isso estamos dando a esse raciocínio o desvio característico de uma derivação, de uma ramificação. É, portanto, uma diferença importante a ser marcada. Então, há de se reiterar: estamos a uma distância, talvez maior, entre autor-escritor e personagem-autor do que na possibilidade estabelecida por Bakhtin. Ainda assim não queremos perder de vista que se constrói mesmo com essa diferença uma transição também plausível. Vejamos: autores-escritores saem da autoria e passam pela escrita para alcançar o texto. Ao chegar no texto temos o encontro com o personagem-autor, que é personagem porque é criação da escrita e é autor porque é músico. Esses personagens-autores têm sua parcela de autoria, portanto. E é ela que nos faz ligar as pontas e encontrar a semelhança com aquele que escreve.

Por que tais semelhanças fazem sentido? Para que as correspondências aconteçam a fim de permitir um ganho analítico que seja pertinente com cada uma das parcelas deste estudo. Pode ser que se esteja indo longe demais, mas esperamos que 
não. Nessa visada dupla de aproximação enxergamos a ação da cidade que está concretamente na vida de quem escreve, mas que reflete na escritura que a recoloca por trás dos personagens retratados. Com essa formulação, e ela inclui evidentemente o elemento literário, a cidade é sempre pano de fundo da matéria estética. Então os reflexos de sua constituição estão por trás do personagem-autor revelando com coerência o Rio de Janeiro vivido também pelos autores-escritores. É disso que estamos querendo falar.

\section{Em Lima Barreto: a cidade e Ricardo Coração dos Outros}

Para dar início a este ponto do trabalho vale destacar que usaremos trechos que se dirigem diretamente a Ricardo Coração dos Outros, mas que para fins de complemento contextual nos apoiaremos também nas questões urbanas que remetem a outros personagens. São essas transições de lugares que mostram os pontos de contato desse músico. Se o subúrbio é seu lugar de morada, existem no texto os outros espaços por ele frequentados. Comecemos nos apoiando na fala do narrador de Triste Fim de Policarpo Quaresma e sua descrição do subúrbio:

Ricardo Coração dos Outros morava em uma pobre casa de cômodos dos subúrbios. Não era das sórdidas, mas era uma casa de cômodos dos subúrbios. Desde anos que ele a habitava e gostava da casa que ficava trepada sobre uma colina, olhando a janela do seu quarto para uma ampla extensão edificada que ia da Piedade a Todos os Santos. Vistos assim do alto, os subúrbios têm a sua graça. As casas pequeninas, pintadas de azul, de branco de oca, engastadas nas comas verde-negras das mangueiras, tendo de permeio, aqui e ali, um coqueiro ou uma palmeira, alta e soberba, fazem a vista boa e a falta de percepção do desenho das ruas põe no programa um sabor de confusão democrática, de solidariedade perfeita entre as gentes que as habitam; e o trem minúsculo, rápido, atravessa tudo aquilo, dobrando à esquerda, inclinando-se para a direita, muito flexível nas suas grandes vértebras de carros, como uma cobra em pedrouços. (BARRETO, 2011, p. 193)

É nesse lugar social que está Coração dos Outros. E é também onde habitam os pobres em geral. "Aí, nesses caixotins humanos, é que se encontra a fauna menos observada da nossa vida, sobre a qual a miséria paira com um rigor londrino" (BARRETO, 2011, p. 193). Espaços que se modelam em casas de cômodos divididas e subdivididas. Um lugar da gente miserável, das profissões desqualificadas pelo sistema brasileiro. É aí, no morro (bem no alto), que se encontram também:

serventes de repartições, contínuos de escritórios, podemos nos deparar com velhas fabricantes de rendas de bilros, compradores de garrafas vazias, castradores de gatos, cães e galos, mandingueiros, catadores de ervas medicinais, enfim uma variedade de profissões miseráveis que as nossas pequena e grande burguesias não podem adivinhar. (BARRETO, 2011, p. 193) 
Há um enlace desse ambiente de moradia com o trabalho que Ricardo Coração dos Outros exerce através da música. Ele é reconhecido de maneira progressiva e isso se dá nesse contexto periférico. É ali que as coisas começam a tomar um certo vulto. Sabemos disso porque o texto faz menção ao fato de que a fama de Ricardo Coração dos Outros nasceu "limitada a um pequeno subúrbio da cidade" (BARRETO, 2011, p. 89). Um reconhecimento possivelmente restrito a este local em que ele morava: um morro nos arredores de Piedade e de Todos os Santos, em que ao longe, de cima, é possível avistar o trem minúsculo que passa.

Sabemos também, porque isso já foi dito antes no romance, que é com o passar do tempo que seu nome vai conquistando adeptos além do espaço que o cerca. Há um respectivo sucesso que se estende a outras localidades suburbanas. Essa fama chega a regiões como Méier, Piedade e Riachuelo. Então já entendemos um pouco mais da perspectiva de alcance da música e seu valor em outros contingentes urbanos que escapam aos domínios da periferia onde ele habita. Vejamos:

Ricardo, depois de ser poeta e cantor dessa curiosa aristocracia, extravasou e passou à cidade, propriamente. A sua fama já chegava a São Cristóvão e em breve (ele o esperava) Botafogo convidá-lo-ia, pois os jornais já falavam no seu nome e discutiam o alcance de sua obra e de sua poética... (BARRETO, 2011, p. 71-72)

É importante que se saiba que essa gente qualificada como "curiosa aristocracia" é a elite suburbana. É nela que se inclui o Major Quaresma², que possuía jantar e almoço - com "muito feijão, muita carne seca e muito ensopado" (BARRETO, 2011, p. 91). Tal qualificação é, em nossa maneira de observar, um tipo de segmentação das classes que Lima Barreto encontra para definir os sulcos capazes de fragmentar a sociedade por conta do poderio econômico. Há uma preocupação interessante do autor que faz questão de diferenciar os gostos. Quem gosta do quê? A elite burguesa não pode gostar da modinha, por exemplo. Dessa forma, evita-se a aproximação entre o popular e o elitista. Uma marcação evidente da dificuldade que a cidade impõe aos marginalizados de serem aceitos (em suas incursões pelo centro administrativo da cidade, seja pela arte, seja pelo trabalho) nos ambientes em que circulam as figuras de poder na sociedade.

\footnotetext{
${ }^{2}$ Elite suburbana e elite aristocrata são classes que estão postas em pesos diferentes na obra de Lima Barreto. A elite suburbana é aquela que ao desfilar pela Rua do Ouvidor praticamente desaparecia. Tal apagamento se faz assim porque nesse local era a elite aristocrata carioca quem realmente despontava e levava o grande destaque.
} 
Ainda assim, como veremos mais adiante, há um termo usado pelo crítico Bruno Carvalho, a porosidade, que nos faz ver como o Rio de Janeiro - mesmo impondo limites étnicos, de gênero e de classe — deixa-se ceder pela interferência de mundos, se é que assim podemos chamar, sempre existente na vida social carioca. Embora sejam vistos como espaços demarcados e com gostos divergentes, há constantemente uma interpenetração que faz com que autores periféricos acabem de certa forma alcançando lugares onde seriam evitados.

Se visto dessa forma - e aqui voltamos ao tema do reconhecimento do personagem-autor Ricardo Coração dos Outros - estamos aqui supondo que a consequência de sua fama é o que faz com que ele passe a dar aulas para a elite suburbana. Então o ir e vir do personagem leva também sua autoria para lugares antes avessos à sua aceitação. A cidade vai cedendo e permitindo ligações que tentaram ser rompidas pela reforma da cidade, mas que a arte de certa maneira consegue romper ao reconciliar, ao reaproximar.

Além da arte propriamente dita, também temos o avanço que se dá com as aulas. Podemos dizer, portanto, que a música e a prática do ensino musical são duas forças distintas e convergentes para atuar de maneira similar naquilo que se tenta dividir. Esse complemento interessante entre ambas é o que acaba construindo um suporte adicional nesse movimento de interpenetração na qual se incide com uma ruptura do espaço gerando a interferência de um modelo no outro. $\mathrm{O}$ autor considerado marginal consegue se reaproximar (com seus ensinamentos, com seu instrumento e com sua proposta estético-formal) do modelo considerado elitista e assim ultrapassa a limitação dada pelo espaço físico centro-periferia.

Vale a pena lembrar, apenas para que se tenha em conta a informação, que as aulas de música são para os artistas da época um complemento bastante comum. Viver exclusivamente de compor e tocar era algo bastante inatingível para os modelos daquele período. Então o ensino era uma forma de alcançar o sustento e a manutenção de uma situação de vida ${ }^{3}$. E era na casa de Policarpo que Ricardo Coração dos Outros ensinava seu aluno a cantar modinhas e tocar violão. E, pelo que sabemos de Quaresma, essas aulas aconteciam próximo a São Januário, região de São Cristóvão, uma localidade que

\footnotetext{
${ }^{3}$ Lembremos, para fins de comparação, de Inácio Ramos, do conto $O$ machete. O texto de Machado de Assis acaba descrevendo assim o personagem: "Vivia de algumas lições que dava e de alguns meios que lhe advinham das circunstâncias, tocando ora num teatro, ora num salão, ora numa igreja". (MACHADO, 2008, p. 553)
} 
ficava a pouco mais de vinte ou trinta minutos, de bonde, do Centro da cidade. Emendamos com a narração que nos situa quanto ao espaço e quanto ao deslocamento de Quaresma naquilo que é seu ritmo diário. O trecho que se segue é o que abre o romance:

\begin{abstract}
Como de hábito, Policarpo Quaresma, mais conhecido por major Quaresma, bateu em casa às quatro e quinze da tarde. Havia mais de vinte anos que isso acontecia. Saindo do Arsenal de Guerra, onde era subsecretário, bongava pelas confeitarias algumas frutas, comprava um queijo, às vezes, e sempre o pão da padaria francesa.

Não gastava nesses passos nem mesmo uma hora, de forma que, às três e quarenta, por aí assim, tomava o bonde sem erro de um minuto, ia pisar a soleira da porta de sua casa, numa rua afastada de São Januário, bem exatamente às quatro e quinze, como se fosse a aparição de um astro, um eclipse, enfim um fenômeno matematicamente determinado, previsto e predito. (BARRETO, 2011, p. 71-72).
\end{abstract}

Distâncias e deslocamentos. Eis uma importante observação daquilo que se dá na cidade, dos afastamentos que reconhecemos por conta dos bairros mencionados. Temos um centro e, irradiando-se, temos os lugares para onde estão os personagens: Quaresma em um ponto intermediário e o músico Coração dos Outros (o personagemautor) em uma localidade ainda mais distante da região central. Nessa leitura de margem e centro fica interessante perceber que ela traz correspondência ao pareamento daquilo que apontamos no início deste artigo com relação ao esforço de quem precisa sair da periferia para trabalhar. Mas fica nítido também que há uma força, que é da arte, capaz de gerar uma certa reinserção de quem foi apartado espacialmente.

\title{
7 Em João do Rio: a cidade e os músicos ambulantes
}

Já vimos que a mobilidade de Ricardo Coração dos Outros nos traz aspectos consistentes para entender a cidade e seus movimentos de afastamento e reaproximação. Então vamos aproveitar a maneira diferente, e de certa forma um pouco divergente, para olhar como João do Rio retrata alguns dos personagens-autores dessa cidade que ele vê. Músicos ambulantes, como diz o título de sua crônica.

Sendo um escritor adepto da observação, João do Rio tem aquele olhar do flaneur. É por isso que ele escreve sobre a periferia sem fazer parte dela. O caminhar, o observar e o captar do autor é o que nos permite entender a escrita de um ponto de vista que tenta extrair o máximo da realidade que ali se apresenta. Mas com um detalhe importante: a perambulação do autor, nesse caso que estamos tratando, analisa os ambulantes da música que estão no centro da cidade como personagens que chegam de fora, como figuras que se intrometem. João do Rio prefere vê-los como aqueles que não 
são do lugar. E isso se soma aos ares de exaltação que, veremos agora, acontece dessa maneira:

Os músicos vieram todos! Não perde a cidade os seus foros de musical - o

Rio, onde tudo é música, desde a poética música dos beijos à decisiva música de pancadaria.

Novamente à calçada a valsa dos "Sinos" e $O$ Guarani se desarticulam em velhos pianos; novamente sujeitos, que parecem cegos, rodam a manivela dos realejos, estendendo a mão súplice, numa ânsia de miséria; novamente, depois de alguns trechos da sonante "Boêmia", um piresinho de metal se vos oferecerá, desejoso de níqueis. E todos vós que sois bons, e todos vós, que gostais de música, haveis de deplorar os coitados que alegram os outros para viver na miséria, com a alma varada de dor, e todos vós sofrereis a crise de harmonia. Oh! a música!. (RIO, 1997, p. 179-180)

Esses são, portanto, sujeitos que começam a se reapropriar da cidade depois de terem desaparecido por um tempo. O tom muda, se formos comparar, em relação ao que lemos em Triste Fim de Policarpo Quaresma. Muda também a forma de João do Rio interpretar os personagens. Já que imprime uma certa elevação ao movimento de volta desses habitantes da cidade e dá a eles uma característica de distinção valorosa.

Entretanto, se dermos a devida atenção a essa celebração, percebemos que ela está vestindo (sem acobertar) certas informações importantes. O exclamar e promover traz consigo a referência aos sujeitos que "parecem cegos", à imagem da "mão súplice" que pede o dinheiro, ao "piresinho de metal" que fica ao chão para tentar angariar algum sustento para esses que vivem de maneira miserável.

Estamos em outro estilo em relação a Lima Barreto? Sim, estamos. Mas temos como ponto de contato uma palavra importante usada por João do Rio: ambulante. E essa adjetivação é bastante oportuna para apoiar a condição do ir e vir dos personagensautores que tocam nas ruas da crônica em questão. A palavra nos dá o aspecto da transição entre um lugar e outro e isso faz com que nossa leitura das interferências entre centro e periferia se saliente, uma mistura que reforça a condição de mesclas entre sujeitos que foram apartados para outro lugar.

Mesmo que a representação de Lima Barreto encontre maior sustentação na camada periférica e coloque a borda da cidade no centro da narrativa, João do Rio não deixa de nos dar elementos dessa mesma vida. Percebemos bem o projeto administrativo de quem comanda a cidade, no qual os músicos ambulantes são intrusos. Eles não estão onde moram, estão se apropriando do espaço público para que sejam vistos. Então a cidade não é, de certa forma, feita para que eles ali se estabilizem.

Certos de que o texto nos mostra essa condição de deslocamento, ainda assim precisamos reconhecer que João do Rio é um cronista, tem um público que lê seus 
textos e tem uma oscilação que incorpora o jeito de narrar da elite letrada que o lê. O trecho a seguir, que se utiliza do verbo pensar na primeira pessoa do plural, faz notar como a autoria aqui se torna parte do discurso da classe favorecida. É uma forma que se distancia do estilo desses ambulantes e, mais que isso, é uma voz narrativa que faz questão de mostrar que nem tudo está muito mal, que certas personagens possuem condições materiais bastante boas. Vejamos:

\begin{abstract}
Não pensemos, porém, romanticamente, que todos os músicos morrem de fome ao cair das ilusões. Antes pelo contrário. A biografia de cada um serve de assunto a todo o boêmio desejoso de ser feliz. Quem não conhece o Saldanha, um velho português baixo, gordo e cego, que tocava viola há mais de vinte anos com um negro também cego da ilha da Madeira, flautista emérito? Esses dois cegos eram acompanhados por um guitarrista escovado, que tocava, fazia a cobrança e ainda por cima era poeta, compunha as cançonetas". (RIO, 1997, p. 181)
\end{abstract}

Por mais que o autor-escritor tente retirar o peso da diferença, há sim um aspecto que afasta os músicos desse centro. Nessa demonstração da narrativa fica claro que se trata de uma música que invade, que chega em determinada hora, que fica por um determinado tempo. Mas é uma atuação artística temporária, efêmera. Uma execução que vai embora com quem a exerce, que precisa sair no final do dia, que não aceita um estado de permanência naquele ponto onde se manifesta. Existe uma intromissão forçada a se fazer ver, a se fazer ouvir. E que fique claro: independente do estilo, nesse caso. Porque o que está no centro aqui não é necessariamente a canção que tocam, mas a camada da sociedade que representam.

Conforme a crônica avança, surgem elementos que João do Rio prefere positivar nas figuras ambulantes. Então vemos que ele entende essa posição do artista de rua como uma ocupação digna de sucesso, que há nela a possibilidade de sustento qualificado e de possível ganho particular. O que percebemos também é que seu olhar acaba manifestando uma exaltação da arte desses músicos sem deixar de salientar o ganho econômico que tal atividade propicia. O trecho que selecionamos deixa isso mais claro, vejamos: "Pois todo o pessoal enriqueceu. O negro casou em Portugal, o Zás-trás conseguiu tudo com jeito, e eu fui encontrar o Saldanha aposentado, considerado como um velho artista diante de um copo de cerveja" (RIO, 1997, p. 181-182).

Em dado momento o próprio músico (o personagem-autor, sempre é bom lembrar) tem a palavra na crônica e fala das turnês que fez de Norte a Sul do Brasil. Tanto é que menciona o quanto ganhou com seu trabalho junto a seus colegas de profissão. E João do Rio, o narrador dessa história, complementa: "E não se trata de um 
caso esporádico. O resultado é geral” (p. 182). O que sabemos nós? Que generalizar não é uma possibilidade. Principalmente entendendo do lugar do qual falamos, da cidade que está em discussão.

\section{A cidade em movimento}

Feita toda essa incursão para observar a cidade que se transforma, com seus autores e seus personagens, tentamos neste trabalho realizar uma análise que desse conta de cruzar elementos contemporâneos daquela capital brasileira do início do século vinte. Lima Barreto e João do Rio, ambos com capacidades de expressão diferentes, fazem notar detalhes para entender com melhor acuidade a condição social. O que se tentou, e esperamos que esteja claro, foi buscar reconstruir um pouco do momento histórico daquela cidade carioca em transformação e os reflexos disso na condição dos escritores e dos músicos por eles retratados. Um exercício de entendimento de época e de literatura. Chegamos assim aos distanciamentos que a reforma urbana aplicou sobre as classes trabalhadoras, com rompimentos espaciais que geraram autores marginalizados, sejam eles os autores-escritores (na vida) ou os personagens-autores (na representação).

O que se viu foi um Lima Barreto jogado para a margem e um João do Rio que faz um jogo de vaivém estético para se fazer aceito. Características que acabam por se misturar ao estilo narrativo que desagua na maneira de compor seus músicos. O que acontece é que, ambos, fazem refletir a interferência que a arte provoca na cidade. Como se a distância física nunca fosse suficiente para acomodar o artista que resiste. Uma resistência que pode estar na periferia e que chega no centro, como Ricardo Coração dos Outros. Ou ainda, uma periferia que resiste no centro e que lida para ser incorporada antes de ser expulsa, como os músicos ambulantes. Soma-se a isso o fato de serem Barreto e Rio autores afrodescendentes, e João do Rio um autor homossexual. Tais fatores implicam uma inquietude da matéria literária e acabam permitindo perspectivas diferentes aos assuntos que abordam. Seus olhares são de enfrentamento e, de certa forma, dão uma atenção diferente à cidade. Talvez possamos dizer que suas escritas acabaram por gerar uma abertura no meio literário que continham ares de intromissão. Desse jeito foram percebidos nos meios letrados e, consequentemente, nos meios elitistas e políticos. Geraram assim trocas que foram sinônimo de avanço em uma sociedade que não se abre para os mais enfraquecidos. Fizeram da arte de escrever a 
saída para poder ocupar o Rio de Janeiro de maneira inteligente nos espaços intelectuais que antes seriam inviáveis.

Dado esse aspecto da autoria o que se entende? Que a escrita de um autor apartado da consideração estética predominante é muitas vezes uma reação ao modelo vigente através da representação e de seus personagens. Em cada detalhe que consideramos os músicos vistos neste estudo, enxergamos a consequência da marginalização e da exclusão. Temos como ver a luta de quem tenta romper com as barreiras discriminatórias. Se de um lado Lima Barreto faz a periferia ter centralidade na construção de sua forma estética, do outro lado João do Rio joga a periferia no centro criando um tipo menos incisivo e combatente, mas possivelmente com uma penetração que acaba enlaçando opiniões que antes seriam divergentes. Então o papel de ambos, embora distinto, termina por conduzir as ideias para um mesmo fluxo. Porque o que se revela é uma constante tentativa de avanço em um cenário que tenta bloquear, que tenta se opor a visões antagônicas. O que temos com Ricardo Coração dos Outros e com os músicos ambulantes aqui estudados acaba por demonstrar que acontecem trocas entre centro e periferia que tendem a considerar o cruzamento entre classes (ricos e pobres). $\mathrm{E}$ quando a pena é de um autor negro ou de um autor homossexual, questões étnicas e de gênero necessariamente passam a fazer parte do contexto para quem atua com a finalidade de romper com a segregação. É disso que se tentou falar aqui, quando se valorizou aspectos de autoria e quando se construiu a noção de correspondência entre autor-escritor e personagem-autor.

Tendemos assim a concordar com o Rio de Janeiro que Ricardo Carvalho chama de cidade porosa (2019). É por seus movimentos de interação entre classes, pelo carnaval, pela música (que aqui no interessa muito) que a cidade carioca avança da República para a entrada no século vinte. Cidade que é o centro do governo brasileiro e que faz com que se misturem os tipos e sujeitos que nela habitam. Então, ao mesmo tempo em que temos a discriminação e o afastamento, vemos também o espaço urbano como o lugar da oportunidade de protestar através da ação do artista. O músico diz o que precisa dizer e se mistura aos outros modelos porque é nessa cidade repleta de criações múltiplas que a força opressora recebe o rebote de uma crítica feita com inteligência. Crítica que se dá, nesse caso estudado, com o fazer literário que ruma para outros lugares e que rompe a segregação que o poder público tenta instituir. Então a porosidade, mesmo nos momentos adversos, se faz presente e atuante para desfazer a força violenta do poder vigente que discrimina o negro, o pobre, o homossexual. A 
reação vem então através do texto, da música e das artes em geral. Ainda que os retrocessos insistam em permanecer.

\section{Referências}

ANTELO, Raúl. Cronologia. In: RIO, João do. A alma encantadora das ruas. São Paulo: Companhia das Letras, 1997.

ASSIS, Joaquim Maria Machado de. Contos reunidos. Porto Alegre: Pradense, 2008.

BARRETO, Lima. Triste fim de Policarpo Quaresma. São Paulo: Penguin, 2011.

CARVALHO, Bruno. Cidade porosa : dois séculos de história cultural do Rio de Janeiro. Rio de Janeiro: Objetiva, 2019.

FARACO, Carlos Alberto. Aspectos do pensamento estético de Bakhtin e seus pares. Letras de hoje, v. 46, n. 1, p. 21-26, jan./mar. 2011.

GOMES, Renato Cordeiro. João do Rio. Rio de Janeiro: Agir, 2005.

HUNT, Lynn. A invenção dos direitos humanos. Uma história. São Paulo: Companhia das Letras, 2009.

QUIJANO, Aníbal. Colonialidad del poder, eurocentrismo y América Latina. In: LANDER, Edgardo (Org.). La colonialidad del saber: eurocentrismo y ciencias sociales. Perspectivas Latinoamericanas. Buenos Aires: CLACSO, Consejo Latinoamericano de Ciencias Sociales, 2000.

RIO, João do. A alma encantadora das ruas. São Paulo: Companhia das Letras, 1997.

SCHWARCZ, Lilia Moritz. Lima Barreto: triste visionário. São Paulo: Companhia das Letras, 2017.

VAZ, Lilian Fessler; CARDOSO, Elizabeth Dezouzart. Obras e melhoramentos no Rio de janeiro: um debate antigo e um privilégio concorrido. In: BRENNA, Giovanna Rosso Del (organizadora). O Rio de Janeiro de Pereira Passos: uma cidade em questão II. Rio de Janeiro: Index, 1985. 